\title{
CONSIDERAÇÕES ACERCA DA EFICIÊNCIA ENERGÉTICA NA SINALIZAÇÃO AUTOMOTIVA
}

\author{
Carlos Alberto Leite de Moura ${ }^{1}$, Vicente Scopacasa ${ }^{2}$ \\ ${ }^{1}$ Indústrias ARTEB S/A \\ ${ }^{2}$ CONSULED \\ E-mails: carlos.moura@ arteb.com.br, vicente.scopacasa@gmail.com
}

\begin{abstract}
RESUMO
O presente trabalho pretende abordar a sinalização automotiva no contexto da eficiência energética, a partir das tecnologias de fontes luminosas. A ampla difusão dos diodos emissores de luz - LEDs - no mercado automotivo tem sido impactante, pois para além da eficiência energética tem ampliado o potencial inovador para os designers. Nestes aspectos residem as bases para uma reflexão acerca da eficiência energética.
\end{abstract}

Se por um lado os LEDs apresentam menor consumo e maior durabilidade, por outro lado não garantem de per si uma escolha genuína e irretocavelmente sustentável. Uma das razões básicas para isto é a particularidade de cada projeto. Se o foco da concepção de uma lanterna automotiva é o potencial inovador, e com isso entenda-se principalmente o impacto visual de compartimentos ópticos em funcionamento, então pode-se explorar a tecnologia para além da necessidade técnica, uma vez que a finalidade não é apenas a percepção de sinais luminosos mas quão destacados e diferenciados estes dispositivos podem figurar ao serem percebidos.

Nestes termos, o tema indica que as fontes luminosas não representam soluções definitivas, mas possibilidades que requerem contextos determinados de aplicação, algo que o presente estudo irá abordar.

\section{INTRODUÇÃO}

A sinalização automotiva envolve, dentre outras coisas, a conversão de energia elétrica em luz. No contexto da eficiência energética esse fenômeno se caracteriza pela eficiência luminosa, dada em lumens/watts $(\mathrm{lm} / \mathrm{W})$, ou seja, trata-se da relação entre a luz produzida e o consumo necessário a esta produção. No âmbito da eficiência energética, a expectativa crescente é a da máxima redução possível de consumo, uma vez que a luz necessária à segurança veicular permanece fixa por tratar-se de item previsto em normas e leis do seguimento, pautando-se no que é necessário à percepção humana e à consequente segurança, ou seja, faz parte do que já se encontra devidamente padronizado.

Neste contexto, a fonte luminosa ocupa lugar de destaque. Lâmpadas de filamento, lâmpadas de descarga a gás e LEDs constituem o grupo de fontes luminosas comumente empregado em dispositivos luminosos do mercado automotivo, divididos entre os dispositivos de iluminação, composto por faróis principais e auxiliares, e os dispositivos de sinalização, composto por lanternas traseiras, dianteiras e laterais. 
Quando se trata de sinalização, o grupo de fontes luminosas costuma se restringir às lâmpadas de filamento e aos LEDs - não incluindo as lâmpadas de descarga a gás, pois requer menor fluxo luminoso em comparação à iluminação. Os LEDs já se incorporaram à sinalização automotiva há muitos anos, mesmo quando não apresentavam uma eficiência luminosa tão expressiva, como hoje. No que tange ao estado da técnica, hoje é possível produzir cada função da sinalização automotiva com alguns poucos LEDs ou tão somente um único. Esta é uma das razões para a ampla difusão da tecnologia no segmento e, dentre suas vantagens, pode-se destacar aquelas vinculadas à sustentabilidade, sob os aspectos do baixo consumo e da longa vida útil. Complementarmente, o mercado automotivo tem encontrado nesta tecnologia um potencial inovador expressivo, algo que pode ser explorado na proporção da inventividade de designers que, cada vez mais, têm à frente a expectativa do público geral e a competitividade do mercado, ambos os fatores a impor demandas que perpassam itens como funcionalidade, atratividade, inovação etc.

O que nem sempre acompanha tais considerações é que todas as vantagens associadas aos LEDs correspondem a um potencial que, invariavelmente, requer um contexto de uso para ser positivamente explorado. Em si mesmo o LED é apenas mais uma fonte luminosa, sua vantagem competitiva conta com a utilização criteriosa. Logo, faz-se imprescindível a mediação técnica, sobretudo para o uso otimizado ao qual pretendemos nos dirigir mais adiante.

Em se tratando de critérios técnicos para a sinalização automotiva, as Resoluções do CONTRAN [1] e as normas da ABNT são as referências nacionais. Complementarmente, em se tratando de potencial inovador e atrativo, as limitações de uso dos LEDs são mais de ordem comercial do que técnica, razão pela qual a difusão da tecnologia se dá comumente em mercados pioneiros e em veículos de primeira linha. Neste particular reside a ressalva de que se vale a presente abordagem, mais especificamente o aspecto para o qual dirigimos a atenção do leitor, tendo sempre em mente a eficiência luminosa/energética: no emprego tecnicamente otimizado dos LEDs, os exemplos oscilam de maneira expressiva. Neste particular, a flexibilidade da tecnologia LED é passível de avanços e retrocessos, a estes últimos associamos as aplicações em que as soluções aproximam-se das aqui denominadas convencionais, ou seja, com lâmpadas de filamento.

Para tornarmos essa questão mais clara, a seguir veremos um capítulo preliminar a esse tema, a saber: os requisitos de desempenho técnico (fotométrico) do segmento automotivo, requisitos aos quais todos os dispositivos luminosos, sejam eles faróis ou lanternas, submetem-se. Dada a nossa delimitação temática, abordaremos esse tema apenas por meio da sinalização automotiva, sem incluirmos a iluminação.

\section{REQUISITOS TÉCNICOS DA SINALIZAÇÃO AUTOMOTIVA}

Nas Resoluções CONTRAN e normas ABNT encontram-se os requisitos de desempenho fotométrico da sinalização automotiva, com os níveis mínimos e máximos de intensidade luminosa, as cores e os pontos de avaliação das respectivas projeções luminosas. Para nos concentrarmos em um único exemplo, dada a necessária brevidade deste particular, ilustraremos tais requisitos com as informações básicas da lanterna de posição dianteira. Abaixo segue uma imagem extraída da norma ABNT NBR 9296:2014 [2]. 


\begin{tabular}{|c|c|c|c|c|c|c|c|c|c|c|}
\hline \multicolumn{10}{|c|}{ Cima } & \multirow{8}{*}{ 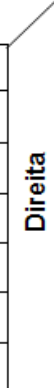 } \\
\hline \multirow{7}{*}{ 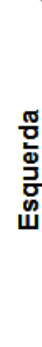 } & Graus & $20^{\circ}$ & $10^{\circ}$ & $5^{\circ}$ & $0^{\circ}$ & $5^{\circ}$ & $10^{\circ}$ & $20^{\circ}$ & Graus & \\
\hline & $10^{\circ}$ & - & - & 20 & - & 20 & - & - & $10^{\circ}$ & \\
\hline & $5^{\circ}$ & 10 & 20 & - & 70 & - & 20 & 10 & $5^{\circ}$ & \\
\hline & $0^{\circ}$ & - & 35 & 90 & 100 & 90 & 35 & - & $0^{\circ}$ & \\
\hline & $5^{\circ}$ & 10 & 20 & - & 70 & - & 20 & 10 & $5^{\circ}$ & \\
\hline & $10^{\circ}$ & - & - & 20 & - & 20 & - & - & $10^{\circ}$ & \\
\hline & Graus & $20^{\circ}$ & $10^{\circ}$ & $5^{\circ}$ & $0^{\circ}$ & $5^{\circ}$ & $10^{\circ}$ & $20^{\circ}$ & Graus & \\
\hline
\end{tabular}

Figura 1 - Tabela de distribuição de intensidade luminosa

No que diz respeito à figura 1 , a primeira e última colunas, assim como a primeira e última linhas, correspondem às coordenadas angulares da projeção luminosa. Os demais valores correspondem ao percentual da intensidade luminosa mínima $(4 \mathrm{~cd})$. Deste modo a maior intensidade estará no centro da projeção luminosa, apresentando redução gradual às extremidades dispostas vertical e horizontalmente.

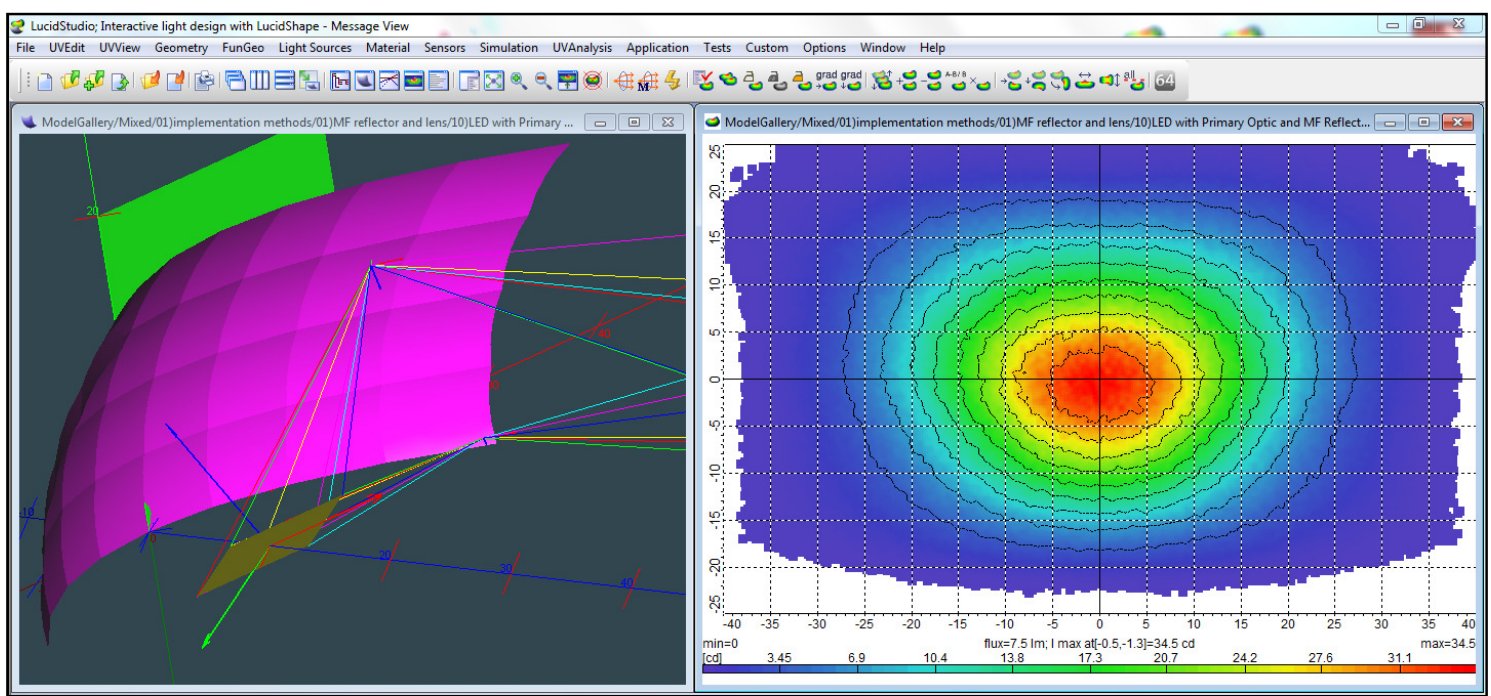

Figura 2 - Imagem de software de CAE (engenharia auxiliada por computador)

Quanto à figura 2, à esquerda tem-se o sistema óptico básico: LED e refletor. À direita tem-se uma tela de avaliação fotométrica com um sensor óptico. Ao fim das análises computacionais tem-se a relação de pontos fotométricos com os valores obtidos de acordo com a distribuição luminosa propiciada pela superfície do refletor óptico. A esta distribuição luminosa impõemse os critérios de valores mínimos e máximos da intensidade luminosa, como exemplificado pela figura 3 . 


\begin{tabular}{|c|c|c|c|c|c|c|c|}
\hline \multirow{2}{*}{\multicolumn{2}{|c|}{$\begin{array}{l}\text { Ângulos de } \\
\text { medição }\end{array}$}} & \multicolumn{6}{|c|}{ Lanterna } \\
\hline & & \multicolumn{2}{|c|}{$\begin{array}{c}\text { Posição e } \\
\text { delimitadora } \\
\text { dianteiras }\end{array}$} & \multicolumn{2}{|c|}{$\begin{array}{c}\text { Posição e } \\
\text { delimitadora traseiras }\end{array}$} & \multicolumn{2}{|c|}{ Freio } \\
\hline v & $\mathrm{H}$ & Mínimo & Máximo & Mínimo & Máximo & Mínimo & Máximo \\
\hline \multirow{2}{*}{$10 \mathrm{C}$} & $5 \mathrm{E}$ & 0,8 & 60 & 0,4 & 12 & 8 & 100 \\
\hline & $5 \mathrm{D}$ & 0,8 & 60 & 0,4 & 12 & 8 & 100 \\
\hline \multirow{5}{*}{$5 \mathrm{C}$} & $20 \mathrm{E}$ & 0,4 & 60 & 0,2 & 12 & 4 & 100 \\
\hline & $10 \mathrm{E}$ & 0,8 & 60 & $0,4^{b}$ & 12 & $8^{\circ}$ & 100 \\
\hline & V & 2,8 & 60 & $1,4^{b}$ & 12 & $28^{\circ}$ & 100 \\
\hline & $10 \mathrm{D}$ & 0,8 & 60 & $0,4^{\circ}$ & 12 & $8^{\circ}$ & 100 \\
\hline & $20 \mathrm{D}$ & 0,4 & 60 & 0,2 & 12 & 4 & 100 \\
\hline \multirow{5}{*}{ H } & $10 \mathrm{E}$ & 1,4 & 60 & $0,7^{\circ}$ & 12 & $14^{\circ}$ & 100 \\
\hline & $5 \mathrm{E}$ & 3,6 & 60 & $1,8^{\circ}$ & 12 & $36^{\circ}$ & 100 \\
\hline & $\mathrm{V}$ & 4,0 & 60 & $2,0^{\circ}$ & 12 & $40^{\circ}$ & 100 \\
\hline & $5 \mathrm{D}$ & 3,6 & 60 & $1,8^{\circ}$ & 12 & $36^{\circ}$ & 100 \\
\hline & $10 \mathrm{D}$ & 1,4 & 60 & $0,7^{\circ}$ & 12 & $14^{\circ}$ & 100 \\
\hline \multirow{5}{*}{$5 \mathrm{~B}$} & $20 \mathrm{E}$ & 0,4 & 60 & 0,2 & $12^{\mathrm{a}}$ & 4 & 100 \\
\hline & $10 \mathrm{E}$ & 0,8 & 60 & $0,4^{\circ}$ & $12^{\mathrm{a}}$ & $8^{\circ}$ & 100 \\
\hline & $\mathrm{V}$ & 2,8 & 60 & $1,4^{b}$ & $12^{\mathrm{a}}$ & $28^{\circ}$ & 100 \\
\hline & $10 \mathrm{D}$ & 0,8 & 60 & $0,4^{b}$ & $12^{\mathrm{a}}$ & $8^{\circ}$ & 100 \\
\hline & $20 \mathrm{D}$ & 0,4 & 60 & 0,2 & $12^{\mathrm{a}}$ & 4 & 100 \\
\hline \multirow{2}{*}{$10 \mathrm{~B}$} & $5 \mathrm{E}$ & 0,8 & 60 & 0,4 & $12^{\circ}$ & 8 & 100 \\
\hline & $5 \mathrm{D}$ & 0,8 & 60 & 0,4 & $12^{\circ}$ & 8 & 100 \\
\hline
\end{tabular}

Figura 3 - Tabela de valores fotométricos

Da figura 3, relativa à tabela de valores fotométricos da ABNT NBR 9296:2014, destacamos os ângulos de medição e os valores, mínimos e máximos, de intensidade luminosa previstos para a função posição dianteira, ora exemplificada. Esta tabela de valores fotométricos resulta das informações apresentadas na figura 1, acrescidas dos valores mínimos e máximos. Vejamos agora uma breve abordagem das fontes luminosas que equipam os dispositivos de sinalização automotiva.

\section{FONTES LUMINOSAS PARA A SINALIZAÇÃO AUTOMOTIVA}

A norma ABNT NBR 16231:2013 [3] trata das fontes luminosas do mercado automotivo brasileiro, mais especificamente das lâmpadas de filamento, com suas características dimensionais, luminosas, elétricas etc. Tais parâmetros dão subsídios aos projetos ópticos, especialmente no que tange às informações acerca do fluxo luminoso e dimensões da lâmpada. A referência normativa internacional é o regulamento de número 37 das nações unidas [4]. 


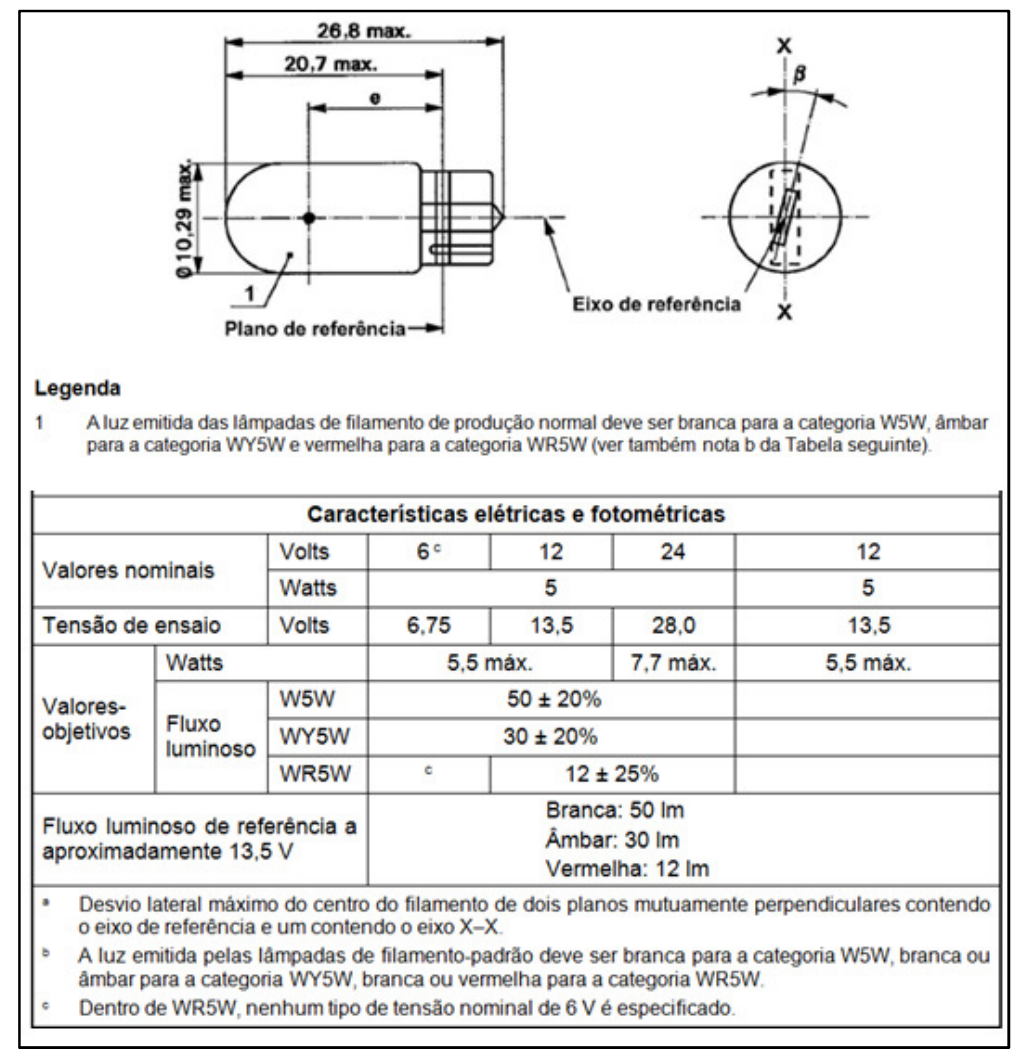

Figura 4 - Folha técnica da lâmpada W5W.

A figura 4 ilustra parte das informações técnicas acerca da lâmpada automotiva modelo W5W, comumente utilizada em compartimentos ópticos de funções sinalizadoras. Cada fabricante da lâmpada W5W divulga sua própria folha técnica (data sheet), havendo variações na disposição das informações, porém nenhum deles conflita com o disposto nos regulamentos e normas de referência na medida em que, estes últimos, dão os subsídios gerais para a homologação do modelo de qualquer fabricante.

No que diz respeito aos LEDs automotivos, as informações e parâmetros para projetistas encontram-se apenas nas folhas técnicas (data sheets) de cada fabricante. Desta forma, ao se tornarem informações veiculadas por diferentes fabricantes, as mesmas não se apresentam de modo padronizado. Um exemplo, significativo para o presente tema, é o seguinte: nem todos os fabricantes informam os valores mínimos de fluxo luminoso, em vez disto declaram os valores típicos. Esta prática diversificada decorre de um produto que, diferentemente das lâmpadas de filamento, caracteriza-se pela incessante expansão tecnológica, marcada por inovações que dificultam ou mesmo dispensam atividades classificatórias e padronizadoras, algo mais compatível com uma tecnologia estável e que alcançou algo próximo a seu limite, enfim, menos passível de inovações.

Outras especificidades dos LEDs são os denominados bin codes [5], ordem classificatória, realizada durante o processo de fabricação, feita para agrupar as diferentes margens de fluxo luminoso, cor e temperatura de cor. Mediante esta seleção o projetista pode estabelecer o grupo de LEDs que atende aos requisitos fotométricos de cada projeto. Deste modo é possível adquirir apenas o grupo de LEDs com fluxo luminoso mínimo necessário. O problema resultante é que, quanto mais específica e estreita for a faixa entre o mínimo e o máximo, mais onerosa será a aquisição, pois tem-se acesso ao item que para o próprio fabricante custa mais, por conta da seleção. Assim, a prática otimizada na engenharia de projetos é aquela em que pode-se trabalhar com faixas mais amplas de fluxo luminoso. 
Para a obtenção de uma projeção luminosa adequada aos requisitos normativos e legais já apresentados, faz-se necessário ter em conta as margens mínima e máxima para a função específica que se pretende desenvolver, seja ela de sinalização ou de iluminação. Este tipo de informação decorre de cálculo. Pautado no que a norma exige em intensidade numa dada projeção luminosa, o projetista determina o equivalente em fluxo luminoso, considerando os rendimentos dos componentes ópticos, as perdas com componentes funcionais e ornamentais etc. No caso dos LEDs, alguns fabricantes já elaboraram material informativo com valores mínimos estimados de fluxo luminoso, informação que pode servir de referência inicial, e damos ênfase ao termo "inicial" porque depende sempre de validação em simulações ópticas, por meio de ferramentas CAE, somente estas podem integrar todas as variáveis e especificidades do projeto, atestando a estimativa em bases contextualizadas.

\begin{tabular}{|c|c|c|c|c|}
\hline Função & $\begin{array}{l}\text { Especificação } \\
\text { ECE }\end{array}$ & Cor & $\begin{array}{l}\text { Intensidade luminosa } \\
\text { mínima }\end{array}$ & $\begin{array}{l}\text { Fluxo luminoso } \\
\text { mínimo }\end{array}$ \\
\hline \multirow[t]{3}{*}{$\begin{array}{l}\text { Direção } \\
\text { dianteira }\end{array}$} & $\begin{array}{l}\text { Regulamento 6, } \\
\text { Categoria } 1\end{array}$ & Âmbar & $175 \mathrm{~cd}$ & $15,9 \mathrm{~lm}$ \\
\hline & $\begin{array}{l}\text { Regulamento 6, } \\
\text { Categoria 1a }\end{array}$ & Âmbar & $250 \mathrm{~cd}$ & $22,6 \mathrm{~lm}$ \\
\hline & $\begin{array}{l}\text { Regulamento 6, } \\
\text { Categoria } 1 \mathrm{~b}\end{array}$ & Âmbar & $400 \mathrm{~cd}$ & $36,3 \mathrm{~lm}$ \\
\hline $\begin{array}{l}\text { Posição } \\
\text { dianteira }\end{array}$ & Regulamento 7 & Branca & $4 \mathrm{~cd}$ & $0,41 \mathrm{Im}$ \\
\hline
\end{tabular}

Figura 5 - Tabela com valores de fluxo luminoso mínimo necessário para cada função.

Em continuidade ao mencionado acima, abordaremos adiante as estratégias ópticas de que se valem os projetistas para assegurar o desempenho requerido pelos critérios ora apresentados.

\section{LÂMPADAS E LEDs}

Para que se torne compreensível o que buscaremos elucidar no decorrer das próximas páginas, faz-se necessário tratar minimamente das diferenças - relevantes para projetos ópticos - entre lâmpadas e LEDs. O potencial e as limitações inerentes a cada fonte luminosa, ainda que desconhecidos teoricamente, se tornam claros no decorrer dos esforços para se viabilizar tecnicamente um dispositivo luminoso.

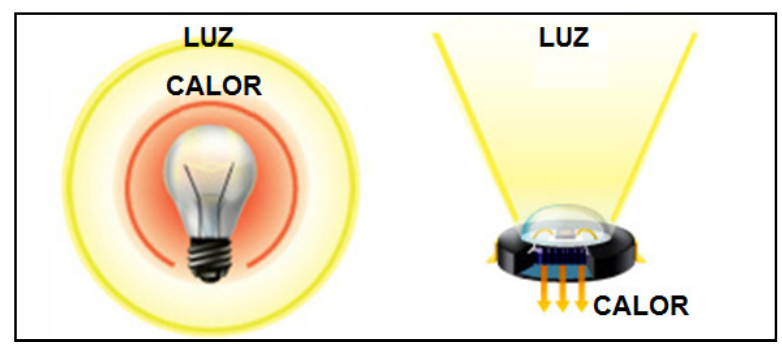

Figura 6 - Diferenças entre lâmpada e LED.

A figura 6 ilustra a relação entre propagação de luz e calor, tanto na lâmpada de filamento quanto no LED. As propagações esférica - fonte isotrópica - ou cônica de luz repercutem de 
modos distintos no projeto óptico. Enfim, projetos ópticos diferem por vários fatores, um dos principais é o relativo à fonte luminosa, como ilustra a figura 7.

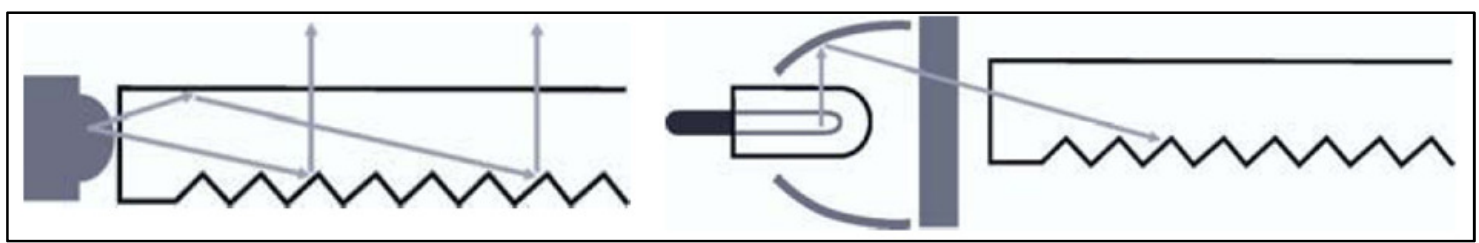

Figura 7 - Dois projetos com guia de luz. À esquerda, LED. À direita, lâmpada.

A figura 7 ilustra duas diferentes soluções ópticas a partir de uma mesma guia de luz (light guide). Neste caso o resultado final, em um farol ou em uma lanterna, é o mesmo para quem observa a função luminosa acesa, porém, na viabilidade técnica, as diferenças entre as fontes luminosas, exemplificadas na figura 6 , resultam em particularidades na construção do produto. A necessidade de coletar e redirecionar os raios luminosos à guia de luz resulta, se utilizada uma lâmpada, em uso de óptica secundária, com perfil parabólico.

Pelas diferenças acima apresentadas, entende-se melhor a ampla difusão dos LEDs na sinalização automotiva. Além da eficiência energética, de modo geral, eles potencializam a inovação através de especificidades tais como: compactação, luz propagada em diferentes perfis, diversidade cromática - branco, rubi, âmbar - e de temperaturas de cor $-4000 \mathrm{~K}$, $5000 \mathrm{~K}$ - etc. O que não costuma estar igualmente difundidas são as reduções deste potencial por meio de fatores que ultrapassam a esfera puramente técnica, embora a ela respondam, trata-se de fatores concernentes às diretrizes de cada projeto. Veremos a seguir diferentes configurações estéticas que resultam em diferentes configurações ópticas, pautadas no atendimento de aspectos visuais variados, e que resultam em casos variados de eficiência energética.

\section{CONFIGURAÇÕES ÓPTICAS NA SINALIZAÇÃO AUTOMOTIVA}

Uma vez consideradas as diferenças essenciais acerca das fontes luminosas, especialmente as diferenças atreladas às soluções ópticas, cumpre agora tratarmos especificamente de como tais soluções são configuradas.

De modo geral o trabalho realizado pelo projetista óptico é o de coletar, da forma mais otimizada possível, os raios luminosos da fonte utilizada e projetá-los tal como é requerido pelas referências normativas e legais. Em se tratando de lâmpadas, a configuração óptica mais comum, pelas razões que vimos acima, é a de refletor parabólico acrescido de lente, podendo haver superfície óptica, apta a distribuir a luz coletada pela parábola, no próprio refletor ou na lente, como ilustra figura 8. 

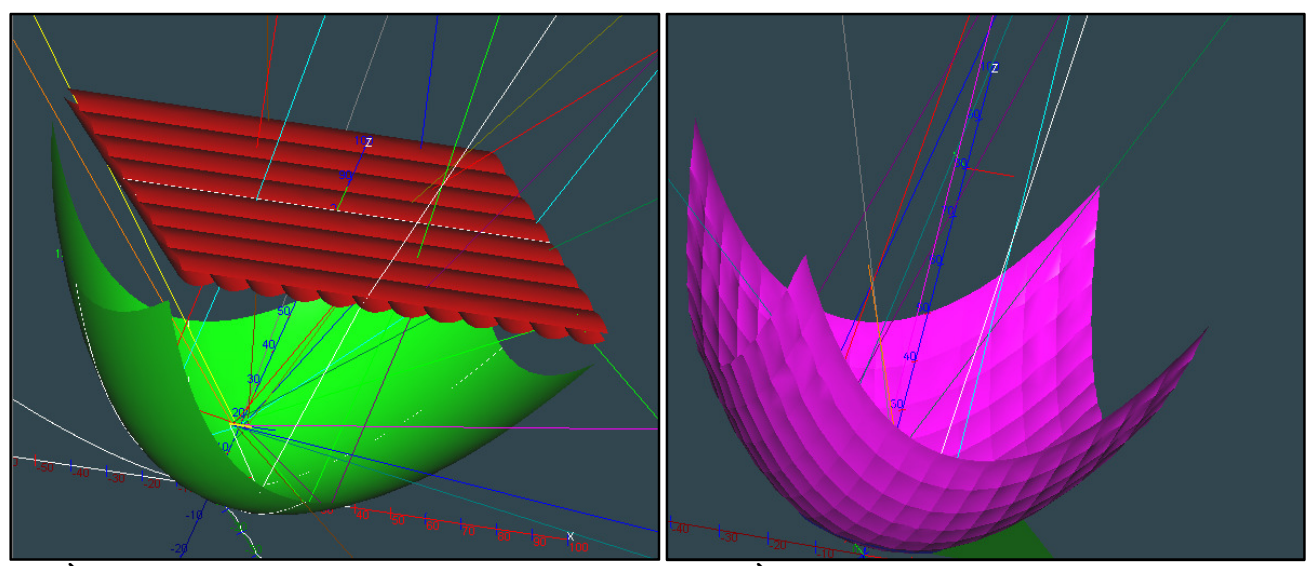

Figura 8 - À esquerda, parábola e lente com óptica. À direita, refletor parabólico com óptica.

Na figura 9 constam algumas das alternativas de configuração óptica para o direcionamento da luz do LED.

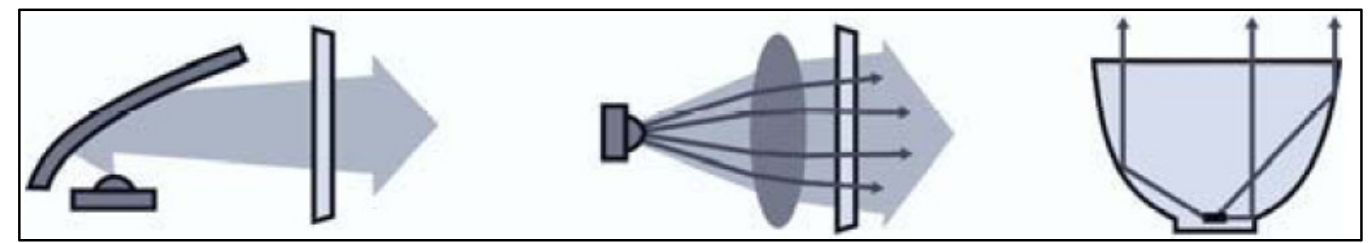

Figura 9 - Da esquerda à direita: reflexão, refração e reflexão interna total (TIR).

Para além destes exemplos, vale ressaltar que muitas vezes a configuração óptica resulta de uma diretriz de desempenho visual, oriundo da concepção estética que envolve o veículo como um todo. Em alguns casos busca-se acendimento pontual, vários pontos luminosos na área visível do compartimento e, em outros casos, tem-se por meta a obtenção de acendimento homogêneo, conforme ilustrado pela figura 10. Esta segunda condição é particularmente difícil e problemática quando se considera áreas grandes, superfícies iluminantes que ocupam expressiva proporção da área total da lanterna ou do farol.

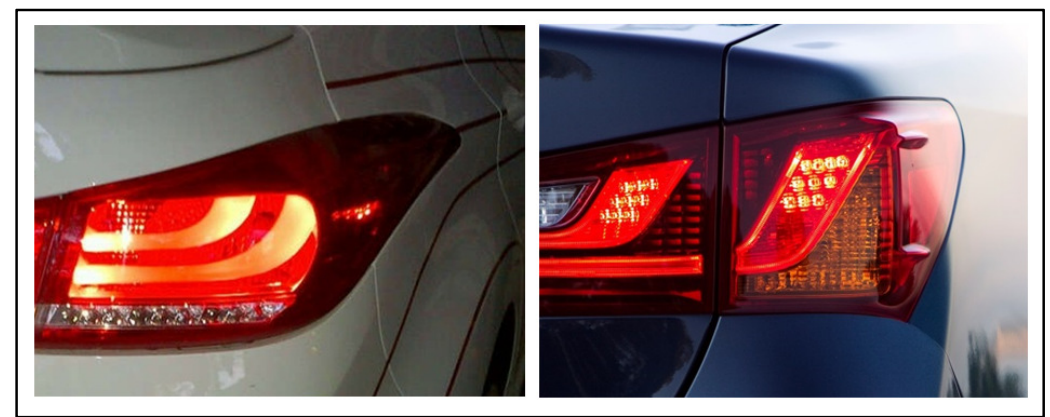

Figura 10 - À esquerda, superfície iluminada homogeneamente. À direita, superfície composta por alguns pontos iluminados.

Nossa abordagem, voltada à eficiência energética na sinalização automotiva, reside nos casos em que a configuração óptica é feita de modo a atender critérios estéticos, casos que resultam em aumento do consumo elétrico, por conta do maior fluxo luminoso requerido a um conceito de iluminamento específico como, por exemplo, o homogêneo em área óptica ampliada. Para tanto, ilustraremos a questão através de três exemplos: a) lâmpada de filamento modelo W5W 
em refletor de farol baixo; b) LED em guia de luz (light guide) acrílica; c) guia complexa, com maior superfície iluminante e refletor integrado.

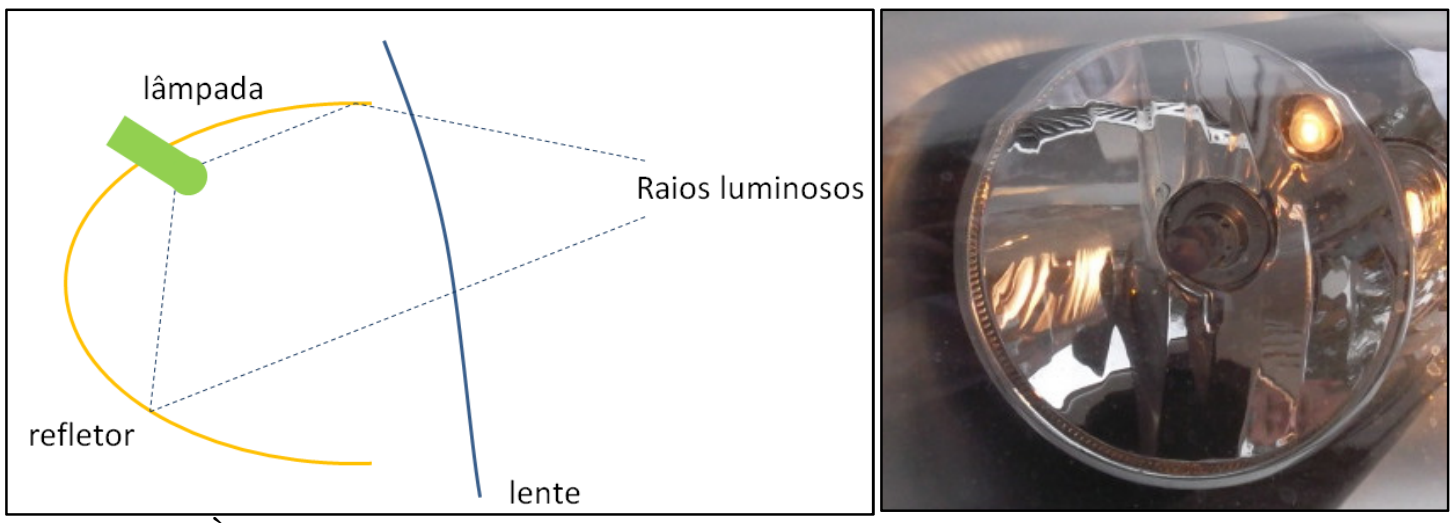

Figura 11 - À esquerda, configuração A e, à direita, condição visual em amostra.

A configuração A é a mais comum, amplamente empregada no Brasil. Seu propósito é predominantemente funcional e técnico, desvinculado do estético. Em alguns casos busca-se, quando muito, uma versão de lâmpada de filamento com luz branca de tonalidade azulada.

A vantagem deste tipo de configuração é o baixo custo, fruto de sua simplicidade. $\mathrm{O}$ compartimento óptico em geral não é dedicado à função posição, utiliza-se comumente um compartimento óptico projetado para a função facho baixo e/ou alto. A desvantagem é a carência de um apelo estético, o propósito de tornar o veículo perceptível é cumprido, porém a sinalização não agrega um destaque adicional, um estilo próprio a esta percepção. Outra desvantagem, sob a perspectiva da eficiência energética, é que se trata de um sinal luminoso que consome 5 watts. No estágio atual da tecnologia LED, é possível cumprir essa função com menos de 1 watt.

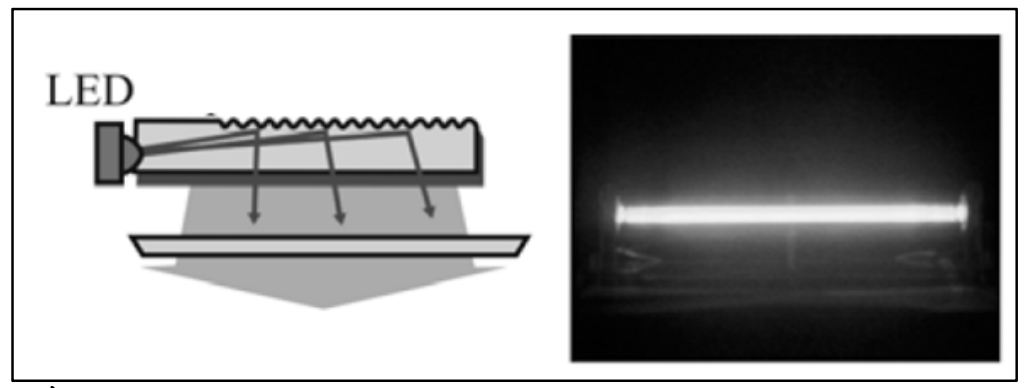

Figura 12 - À esquerda, configuração B e, à direita, condição visual em amostra.

A configuração B tem por característica principal a promoção de sinalização destacada, através de guia de luz apta a contornar compartimentos ópticos das mais variadas formas. Trata-se, grosso modo, de um tubo de material plástico - de formato e comprimento variável e diâmetro geralmente constante - cujas faces ópticas conduzem a luz do LED de uma extremidade à outra. Vantagens: custo intermediário, entre as configurações $\mathrm{A}$ e $\mathrm{C}$, consumo elétrico médio equivale a $1 / 5$ da configuração $\mathrm{A}$, potencial inovador e estilizado conferido ao projeto do farol e/ou lanterna, variadas temperaturas de cor na luz branca. As desvantagens são aquelas associadas a um item de complexidade média: solução eletrônica automotiva, molde de injeção plástica para a guia de luz, material plástico com boas propriedades ópticas etc. 


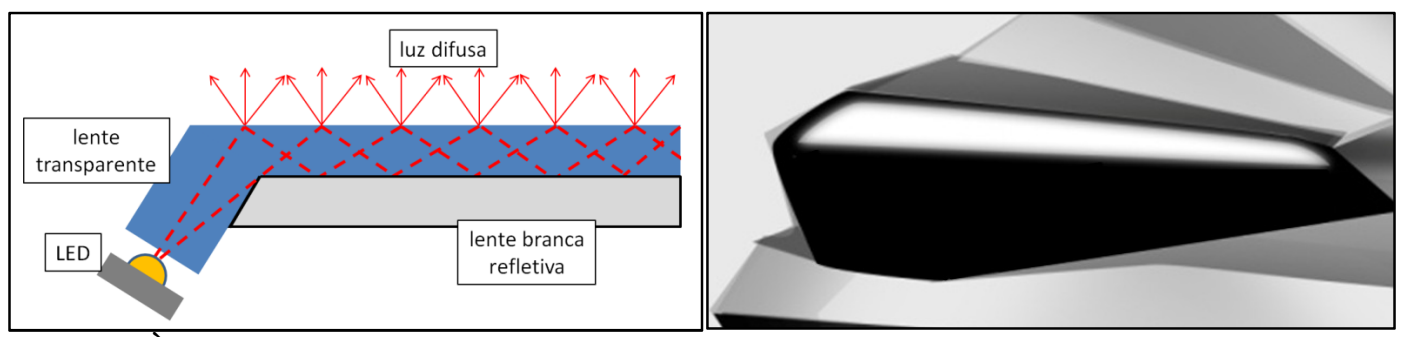

Figura 13 - À esquerda, configuração C e, à direita, imagem de carro conceito com função análoga

A configuração $\mathrm{C}$ caracteriza-se pelas qualidades da configuração $\mathrm{B}$, acrescidas do diferencial que é também o elemento complicador: maior área de superfície iluminante, composta por duas lentes de espessuras variáveis e geometria complexa, apta a acompanhar as linhas de construção do veículo. Compõe-se basicamente por: a) lente transparente de material com alto índice de transmitância e com textura na face de saída dos raios luminosos, para a máxima difusão e consequente homogeneidade; b) lente branca com alto índice de reflexão, para conduzir a luz do LED por toda a extensão do conjunto óptico; c) LED com fluxo luminoso de média e/ou alta potência, cujo consumo varia em torno de três vezes acima da configuração $\mathrm{B}$ e, por esta razão, pode requerer um maior número de LEDs. A fim de ilustrarmos um pouco mais a homogeneidade ligada à configuração $\mathrm{C}$, vejamos a figura 14.

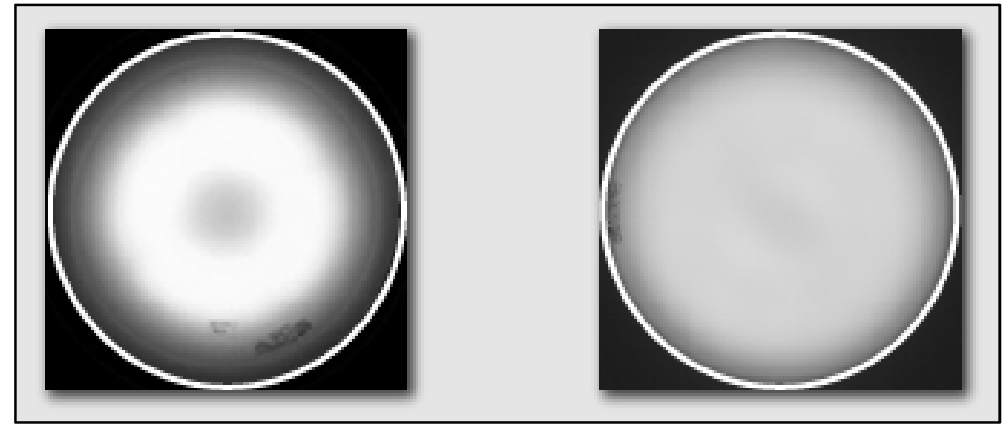

Figura 14 - À esquerda, contraste entre zona clara e escura. À direita, homogeneidade em boa parte da superfície iluminante.

Tanto as propriedades ópticas dos materiais utilizados como a solução óptica de cada configuração respondem, de formas variadas, por uma maior ou menor homogeneidade da superfície iluminante. A vantagem da configuração $C$ reside no benefício mútuo concedido às esferas subjetiva e objetiva, pois se por um lado confere o destaque e o estilo diferenciado ao veículo, por outro assegura maior área de superfície iluminante, enfim, maior visibilidade ao veículo. Em contrapartida as desvantagens residem no maior custo dentre as três configurações e consumo elevado se levarmos em conta que se trata de uma solução a LED. Ou seja, neste caso, o uso do LED desvincula-se - por vias indiretas - da expectativa tipicamente associada à tecnologia dos diodos emissores de luz, ou seja, a eficiência energética. Sem dúvida toda solução a LED tende a apresentar um diferencial na eficiência energética, porém um eventual consumo excessivo pode decorrer a partir de determinadas metas de design.

Considerando-se o quadro abaixo, constata-se que a eficiência energética de uma solução óptica a LED pode ser, em circunstâncias específicas, comparável a uma solução óptica convencional que tenha uma lâmpada de filamento como fonte luminosa. 
Tabela 1 - Configurações A, B e C.

\begin{tabular}{|c|c|c|c|}
\hline & $\begin{array}{l}\text { Configuração A } \\
\text { lâmpada W5W + } \\
\text { refletor metalizado }\end{array}$ & $\begin{array}{l}\text { Configuração B } \\
\text { LED + guia de luz }\end{array}$ & $\begin{array}{l}\text { Configuraçãa C } \\
\text { LEDs + guia de luz } \\
\text { composta (duas lentes) }\end{array}$ \\
\hline $\begin{array}{l}\text { fluxo luminoso da } \\
\text { fonte }\end{array}$ & $50 \mathrm{~lm}$ & $100 \mathrm{~lm}$ & $\begin{array}{l}300 \mathrm{~lm} \\
(3 \mathrm{LEDs} \text { de } 100 \mathrm{~lm})\end{array}$ \\
\hline potência & $5 \mathrm{~W}$ & 1,3 W (1 LED) & $\begin{array}{l}4 \mathrm{~W} \text { (3 LEDs de 1,3 } \\
\text { watts, com dissipador } \\
\text { de alumínio) }\end{array}$ \\
\hline $\begin{array}{l}\text { Intensidade } \\
\text { luminosa média }\end{array}$ & $14 \mathrm{~cd}$ & $8 \mathrm{~cd}$ & $20 \mathrm{~cd}$ \\
\hline $\begin{array}{l}\text { Configuração } \\
\text { óptica }\end{array}$ & $\begin{array}{l}\text { Sem óptica dedicada, } \\
\text { pois utiliza a óptica do } \\
\text { farol principal }\end{array}$ & $\begin{array}{l}\text { Guia de luz única, com } \\
\text { diâmetro constante, } \varnothing 6 \\
\text { mm, em todo o contorno } \\
\text { do farol. }\end{array}$ & $\begin{array}{l}\text { Guia de luz dupla, de } \\
\text { espessuras e formas } \\
\text { variadas (em todo o } \\
\text { contorno do farol) }\end{array}$ \\
\hline
\end{tabular}

Considerando-se exclusivamente o critério normativo e legal, que estabelece 4 cd como valor mínimo de intensidade luminosa para a função posição dianteira, percebe-se o superdimensionamento da configuração C. A mesma, ao requerer $300 \mathrm{~lm}$ e resultar em $20 \mathrm{~cd}$ de intensidade luminosa média, se mostra pouco eficiente quando comparada à configuração A que, com apenas 1/6 do fluxo luminoso e tão somente $1 \mathrm{w}$ a mais, alcançou $70 \%$ de sua intensidade luminosa, muito embora apenas $20 \%$ deste valor seja necessário perante as Resoluções CONTRAN e normas ABNT. Enfim, o quadro acima elucida o quanto a configuração A é simples, econômica e energeticamente eficiente em relação à configuração $\mathrm{C}$, esta última complexa e onerosa em relação às outras duas configurações. Complementarmente, a configuração B mescla pontos altos e baixos das outras duas.

Falávamos no início de nossa exposição acerca de aplicações otimizadas e não otimizadas da tecnologia LED. Sob o aspecto exclusivo da sinalização, e tendo em conta a eficiência luminosa no contexto da presente abordagem, a configuração $\mathrm{C}$ não é otimizada, já a configuração B, por mero contraste com a C, é otimizada.

Desta forma, a sinalização automotiva demonstra que a seara de diretrizes estéticas, inerentes e sem dúvida necessárias para o mercado - em função de aspectos que a delimitação temática não nos permite tratar, pode comprometer parte do potencial de eficiência energética ao qual a tecnologia LED está sempre associada. Ressaltamos que a perda de eficiência energética, como na configuração $\mathrm{C}$, está associada à solução empregada e às especificidades de seu contexto de aplicação, e não à tecnologia LED.

\section{CONCLUSÃO}

No presente cenário e nas tendências tecnológicas que impulsionam a sinalização automotiva, o LED reafirma frequentemente seu caráter promissor ao possibilitar, à inventividade de designers, o alcance da viabilidade técnica, qualidade decisiva em um mercado cada vez mais competitivo. 
No entanto o imenso potencial do LED às vezes oculta a sobreposição expressiva de fatores alheios à funcionalidade, algo que não raro penaliza a eficiência energética de forma a tornar, neste aspecto, uma solução a LED similar a uma solução a lâmpada. Da divulgação científica à popular, o LED sempre está vinculado a questões concernentes à eficiência energética, logo, o contexto de aplicação ora apresentado cumpre, minimamente, a necessária verificação desta associação frente a uma das tendências da sinalização automotiva: superfícies iluminantes homogêneas e cada vez maiores.

Assim, esperamos ter esclarecido o quanto a eficiência energética na sinalização automotiva é um tema multifacetado, envolve fatores que englobam elementos diversos da esfera técnica. Neste sentido, ao ampliarem técnica e esteticamente o leque de opções, os LEDs indicam o quanto é preciso, em termos de eficiência energética, ampliar a perspectiva que engloba estes fatores, não para limitar as esferas técnicas e/ou inventivas, mas para emprega-las de modo consciente e, sempre que possível, sustentável.

\section{REFERÊNCIAS}

[1] RESOLUÇÕES CONTRAN. Disponível em:

http://www.denatran.gov.br/resolucoes.htm Acesso em maio de 2016.

[2] ABNT NBR 9296:2014 - Veículos rodoviários automotores - Lanterna delimitadora, de posição e de freio.

[3] ABNT NBR 16231:2013 - Prescrições uniformes relativas às lâmpadas de filamento para uso em sistemas de iluminação e/ou sistemas de sinalização de veículos rodoviários automotores e seus rebocados.

[4] REGULAMENTO EUROPEU NÚMERO 37. Rev.8 - Filament lamps Disponível em: http://www.unece.org/fileadmin/DAM/trans/main/wp29/wp29regs/updates/R037r8e.pdf Acesso em maio de 2017.

[5] FPS MEDIA - Infographics Binning "LED Binning Explained". Disponível em: https://www.youtube.com/watch?v=SFrodivy6L8 Acesso em maio de 2017. 